\title{
The Effects of Currency and Imports Restrictions on Luxury Advertising in Argentina: Content Analysis of Ads in Argentine Fashion Magazines
}

Juan F. Mundel

West Virginia University

Follow this and additional works at: https://researchrepository.wvu.edu/etd

\section{Recommended Citation}

Mundel, Juan F., "The Effects of Currency and Imports Restrictions on Luxury Advertising in Argentina: Content Analysis of Ads in Argentine Fashion Magazines" (2013). Graduate Theses, Dissertations, and Problem Reports. 224.

https://researchrepository.wvu.edu/etd/224

This Thesis is protected by copyright and/or related rights. It has been brought to you by the The Research Repository @ WVU with permission from the rights-holder(s). You are free to use this Thesis in any way that is permitted by the copyright and related rights legislation that applies to your use. For other uses you must obtain permission from the rights-holder(s) directly, unless additional rights are indicated by a Creative Commons license in the record and/ or on the work itself. This Thesis has been accepted for inclusion in WVU Graduate Theses, Dissertations, and Problem Reports collection by an authorized administrator of The Research Repository @ WVU. For more information, please contact researchrepository@mail.wvu.edu. 
The Effects of Currency and Imports Restrictions on Luxury Advertising in Argentina: Content Analysis of Ads in Argentine Fashion Magazines

\author{
Juan F. Mundel
}

\author{
Thesis submitted to the \\ Perley Isaac Reed School of Journalism \\ at West Virginia University \\ in partial fulfillment of the requirements \\ for the degree of
}

Master of Science

in

Journalism

Hongmin Ahn, Ph.D., Chair

Diana Martinelli, Ph.D.

Rita Colistra, Ph.D.

Graham Peace, Ph.D.

Morgantown, West Virginia

2013

Keywords: Luxury, Advertisement, Argentina, Restrictions

Copyright 2012 Juan F. Mundel 


\section{ABSTRACT \\ The Effects of Currency and Imports Restrictions on Luxury Advertising in Argentina: Content Analysis of Ads in Argentine Fashion Magazines Juan F. Mundel}

While many scholars have examined the relationships between public policies and advertising, few have studied such relationships in Latin America. This study explores how the limitations on foreign exchange transactions in Argentina affect the advertising strategies implemented by luxury brand advertising. A content analysis of 398 luxury brand ads placed in fashion magazines in Argentina was conducted to investigate changes in the luxury ads in the wake of the currency and import restrictions in Argentina. The analysis indicates that, during the restrictions, ads were less likely to convey strong emotional messages than before. Also, the result suggests that the creative strategies leaned to a more sober and simple approach during the restrictions era. Furthermore, the findings suggest that upon the restrictions implementations, ads used different visual cues as a way to engage the consumer and evoke stronger exclusivity, luxury, and global feelings. The results of the study confirm that changes in economic status serve as considerable factors wherein advertising has been transformed, as advertising has long been considered a mirror of the society. 
For my parents 


\section{ACKNOWLEDGEMENTS}

This thesis can be attributed to the great pleasure of having attended the Perley Isaac Reed School of Journalism at West Virginia University, and to the support and friendship of my classmates in the program.

In addition, I need to thank Alicia Jurado Ramirez and Christian McCarty, whose friendship made my time in the United States an unforgettable experience. I am extremely grateful for your advice, kindness, unconditional support, and love.

The professors on my committee deserve all the possible appreciation for understanding my unconventional deadline pressures and still be willing to help with my work. Your input, personal dedication, suggestions, and comments made an enormous difference to this thesis.

I would especially like to thank Professor Hongmin Ahn for serving as chair and spending endless hours on this study, and for providing me with exhaustive feedback every step of the way.

And finally, it is to my parents, Maria and Oscar, that I dedicate this thesis. You never let the distance get in the way of love and care. Without a doubt, you are the most important role models in my life. 


\section{TABLE OF CONTENTS}

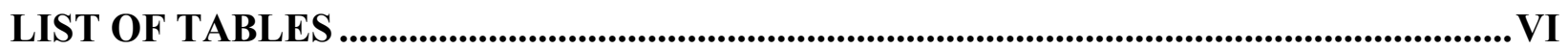

INTRODUCTION

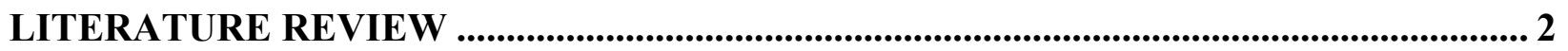

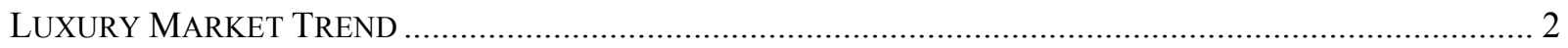

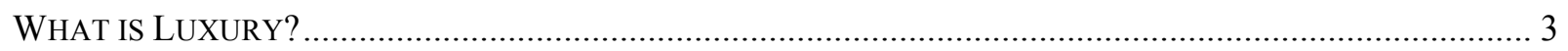

ARGENTINA'S ECONOMY AND LUXURY BRAND MARKET …........................................................ 5

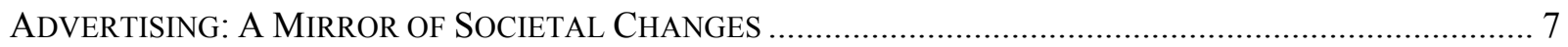

AdVERTISING PSYCHOLOGY: APPEALS, STRATEGIES, AND TONE IN LUXURY BRAND ADVERTISING .... 9

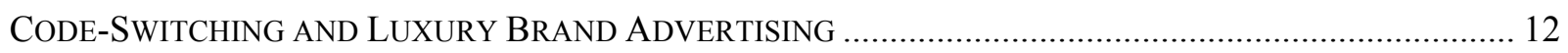

THE Role Of HuMAN MOdEL ETHNiCITY IN LUXURY BRAND AdVERTISING .................................. 13

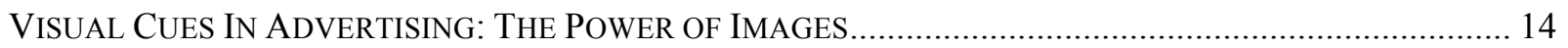

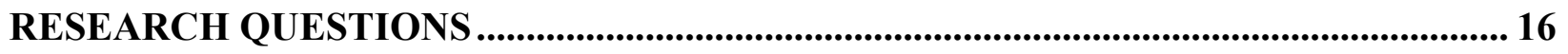

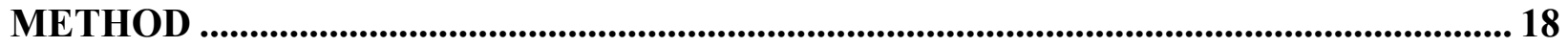

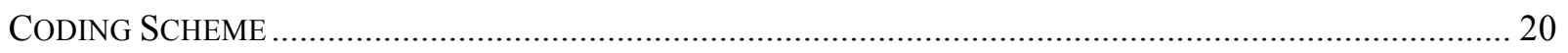

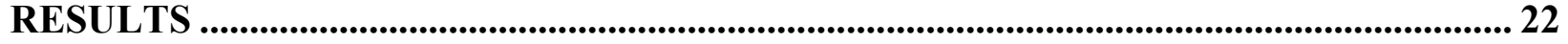

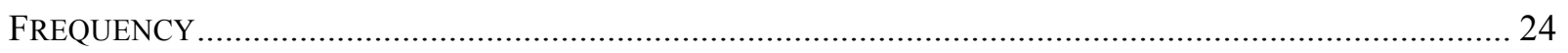

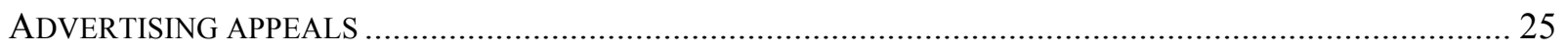

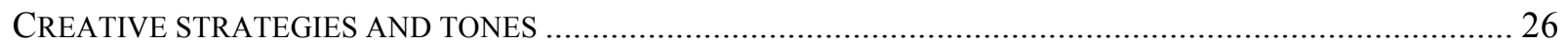

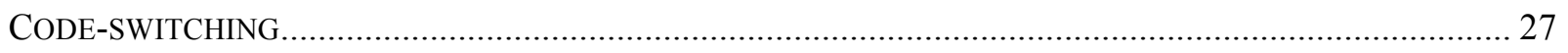

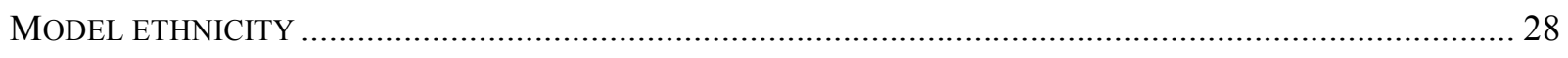

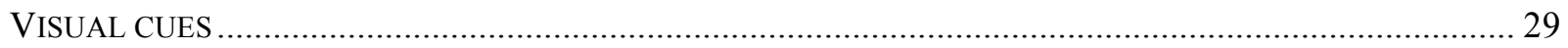

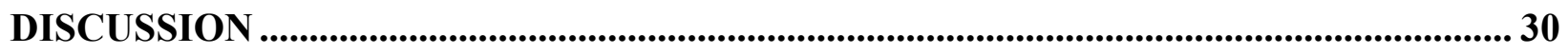

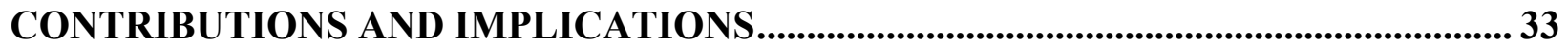

LIMITATIONS AND FUTURE STUDY .................................................................... 34

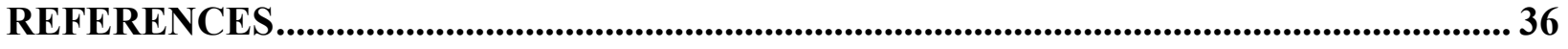

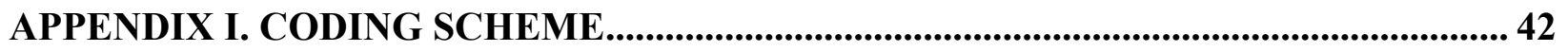




\section{LIST OF TABLES}

TABLE 1: OPERATIONAL DEFINITIONS AND INTERCODER RELIABILITY ....................................... 23

TABLE 2: FREQUENCY AND PERCENTAGE OF UNIQUE LUXURY ADS ON PTC ............................. 25

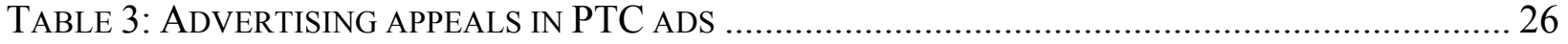

TABLE 4: Presence OF STRATEgIES AND tONES IN PTC ADS ................................................. 27

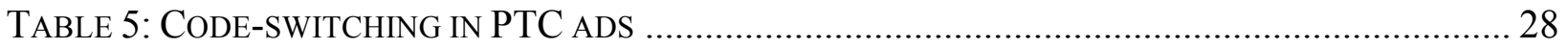

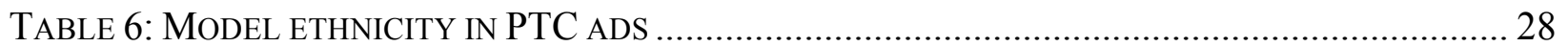

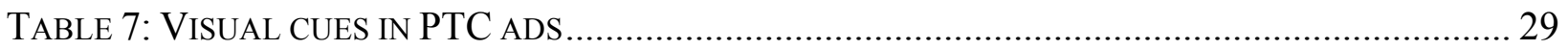




\section{INTRODUCTION}

While much has been documented about luxury marketing strategies in the leading markets, such as Europe and North America (Atwal \& Williams, 2009; Castarede, 2008; Chaddah \& Husband, 2006; Dazinger, 2005; Gardyn, 2002; Holt, 2004; Kapferer \& Bastien, 2009; Petrecca \& Louise, 1999; Sicard, 2003; Silvertein \& Fiske, 2003; Tungate, 2004), little is known about the emerging luxury market in developing countries, particularly in Latin America. Large Latin American countries, such as Brazil, Argentina, and Mexico, where new wealth can be found have great potential to expand luxury markets (Kapferer \& Bastien, 2009). Among the Latin American countries, Argentina is a particularly fertile ground for the rise of luxury brands. Argentina has the highest purchase buying power in the region and is the third largest economy in Latin America (International Monetary Fund, 2011), behind Brazil and Mexico. With a growing upper class population, the luxury market in Argentina has continued to grow (Castano Freeman, 2012).

However, over the past few years, the luxury market in Argentina has experienced radical societal changes. Since the 2001 default on the country's foreign debt, the Argentine government has implemented a number of massive and drastic policies to control foreign currencies as well as revamp the nation's economic growth. The government limited the foreign exchange transactions and enforced restrictions on imports, thereby radically changing Argentines' spending habits. As a result, $14 \%$ of foreign purchases have decreased since the restrictions ( $\mathrm{La}$ Nación, 2012), an estimated amount of US\$38 million.

The effect of such restrictions is particularly strong for luxury brands, most of which are imported from foreign countries. As a result, many luxury goods retailers have left Argentina to avoid import barriers and currency restrictions. Retailers such as Ermenegildo Zegna, Escada, 
and Ralph Lauren have already closed their stores. And French jewelry boutique Cartier is planning to close its shops in Argentina in response to the restrictions (Helft, 2012).

This study examines changes in the luxury ads in Argentina in the wake of the currency and import restrictions, taking into account that advertising has long been considered a mirror reflecting trends and changes in a society (An, 2003; Belk et al., 1985). It is worth investigating how advertising reacts to these unusual economic restrictions. The unprecedented economic changes in Argentina provide a unique lens to explore how a change in public policies affects advertising practice. Therefore, the goal of the study is to explore whether and how the current economic occurrences in Argentina appear to affect the advertising strategies implemented by both domestic and international luxury brands to effectively engage Argentine customers in acquiring the goods in spite of the boundaries established by the government.

To this end, the current study focuses on magazine ads, where most luxury advertising appears (Doran, 2012; Fitzgerald, 2012). The findings of the current study will help to shed light on the effects of economic change as a force to shape advertising. It will also help fill a gap in luxury brand literature by extending the knowledge about luxury marketing in Latin America.

\section{LITERATURE REVIEW}

\section{Luxury Market Trend}

The global luxury market has been growing at an increasing rate since the early 1990s, with the growth rate roughly at 10-15\% annually (Matthiesen $\&$ Phau, 2005). The growth rate has outpaced that of any other consumer goods industries, and the luxury market has become one of the fastest-growing industries in the world (Fionda \& Moore, 2009). Such trends become universal, as developing countries (e.g., China, Russia, Brazil) have emerged into the market (Atwal \& Williams, 2009). 
Many factors influence the growth of the market, including the growing of the wealthy class in developing countries, the increasing buying power among working women, lower production costs (Truong, McColl, \& Kitchen, 2009), and socio-cultural factors such as the media's attention to luxury products (Fionda \& Moore, 2009). Particularly, as a result of production cost reduction, reasonably-priced premium products attract middle-class consumers who have a desire to follow the lifestyles of the richer classes above them; thus, the luxury brands have become more available to the wide range of consumer groups (Atwal \& Williams, 2009).

Traditionally, luxury goods have been categorized into four different segments: fashion, perfumes and cosmetics, wines and spirits, and watches and jewelry. However, as the luxury market has spanned its domain across a variety of product categories, luxury brands now include almost any product or service: from automobiles, hotels, tourism, and private banking to home furnishings (Chevalier \& Mazzalovo, 2008). Among those categories, the fashion industry accounts for the largest portion of luxury goods sales, representing $42 \%$ of sales (Fionda $\&$ Moore, 2009).

\section{What is Luxury?}

In order to examine the luxury market, it is necessary to understand what luxury is. Luxury finds its roots in the very core of the royalty times, where social stratification differentiated the nobility, such as kings, royal family, and priests, from the rest of the people and the working class (Kapferer \& Bastien, 2009). While the history of luxury consumption is thousands of years old, the first forms of luxury 'brand' emerged in the nineteenth century (Chevalier \& Mazzalovo, 2008). The industrial production of the first luxury brands of 
silverware, glassware, and china originated in England and France (e.g., Baccarat, Wedgwood, Lalique) (Nueno \& Quelch, 1998). As a result of the technological advances that make these products massively available, and the increased middle class population "who are no longer at a financial distance from luxury" in the twentieth century (Atwal \& Williams, 2009, p. 339), luxury brands have become "masstige" brands (Truong et al., 2009), which means a downward brand extension.

According to Kapferer and Bastien (2009), with the upcoming of the eighteenth-century rationale and revolutions, the western society turned into the model for which it is known nowadays: each person in a democratic world has an equal chance of succeeding in any aspect of life, and it is up to the self to make a specific destiny through work. On the other hand, the human need for social differentiation has not disappeared, and this is where the luxury industry plays its major role. As the royalty codes are no longer an exclusive index of wealth, brands have become a social marker for stratification, and the only obstacles to reach the desired goods are the limits of people's finances. This process is called "the democratization of luxury" (Kapferer and Bastien, 2009). In line with this thinking, Chevalier and Mazzalovo (2008) define a luxury brand as "one that is selective and exclusive, and which has an additional creative and emotional value for the consumer" (p. 8).

As the demand for luxury brands has risen, luxury consumption has remained of keen interest among scholars who consider it a remarkable cultural trend and an economic activity in contemporary society. Researchers from a variety of disciplines, including anthropology (Douglas \& Isherwood, 1979), cultural psychology (McCracken, 1988; Csikszentmihalyi \& Rochberg-Halton, 1981), psychology (Kemp, 1998; Veblen, 1899), economics (Bagwell \& Bernheim, 1996), and marketing (Dubois et al., 2005), have attempted to understand how and 
why people are persistently seeking "luxury" goods. Despite the impressive body of literature on luxury consumption, there is no consensus among scholars regarding the definition of luxury brands because of difficulties to define what constitutes a "luxury good."

Chevalier and Mazzalovo (2008) recently developed a definition that explains what makes a product a luxury item: "a luxury good must satisfy three criteria: it must have a strong artistic content, it must be the result of craftsmanship, and it must be international” (p. xi). Conceptualized as "conspicuous consumption" by Veblin in 1899, the notion that luxury goods are not functional utilities for satisfying physical needs but rather symbolic utilities for gratifying the psychological craving for status or esteem has been central to the conceptualization of luxury brands. In particular, researchers suggested that primarily these status-seeking motivations led to the growth of luxury consumption in the West during the 1980s and 1990s (Atwal \& Williams, 2009).

\section{Argentina's Economy and Luxury Brand Market}

The recent global phenomenon—-known as the "massification of luxury" (Gomelsky, 2004), in which newly affluent consumers aspire to demonstrate their new socioeconomic position by purchasing the so-called affordable luxuries - has been a driving factor in expanding the luxury market regardless of the region. However, the most influential contact points when it comes to the luxury goods purchase process are closely associated with country-dependent factors, such as economics (Berger, 2012). The luxury market trend in Argentina suggests that this is the case.

Over the past few decades, the luxury market in Argentina has been growing for two main reasons: 1) the competitive currency of the peso (Blejer \& Levy-Yeyati, n.d.) and 2) the 
growing class of highly educated professionals whose sophisticated habits were inherited from their European ancestors (Viteri, n.d.). As the peso matched the value of the US dollar in 1991, the capital inflows and the economic growth expanded consumption to unprecedented records (Rodrik, 2003). In Argentina, it also became customary for the high-middle class and upper class to spend their holidays in New York, Paris, and London, among other major stylish metropolises around the world (Pou, 2000). In addition, the devaluated economies of the surrounding countries, as well as the tax exemptions, represented a very competitive opportunity for the conspicuous consumers to purchase luxury goods at lower prices (Rodrik, 2003).

Unfortunately, this golden era, which influenced the rise of luxury market in Argentina, did not last for long. Argentina struggled to maintain the one-to-one value, which meant a lack of competitiveness for its own exporters. Brazil devalued its currency in 1999 without any kind of anticipatory warnings to its main commercial partner in the region. In addition, the domestic politics of austerity created an unbearable situation for both the nationals and the foreign investors, who had lost hope that the Argentine government would respond to its international constituencies (Rodrik, 2003). Fearing an economic crash, Argentines and foreigners alike started to trade their pesos for dollars. This series of events led to "el corralito financiero," an economic measure implemented by the Minister of Economy, Domingo Cavallo, which froze the totality of bank accounts and forbade the withdrawal of US dollars to prevent a bank run (Rodrik, 2003).

In order to put an end to the economic disaster that happened shortly after the corralito implementation, subsequent governments — Kirchner's in particular — implemented the "pesoification" of the bank deposits, with a conversion scheme of ARS $4=$ USD 1 . Once the Argentine economy naturally bounced back, fostered by the newly gained competitiveness, the 
population re-engaged in bigger expenses and satisfying higher needs, such as foreign travel and the acquisition of luxury products. Yet again, as Rodrik (2003) indicated, the 2009 international financial crisis negatively affected the southern country's population: a series of staggered measures were implemented to protect the country of the global crisis that involved the restrictions of imports, import substitution, limitations on foreign exchange transactions on the payment of dividends abroad, and others. According to Webber (2011), by January 2011, Argentina had already applied non-automatic import licenses to a total of 600 goods, thereby paralyzing the consumer-spending boom the country was experiencing.

Not satisfied with the results of this series of measures, Cristina Kirchner's government imposed advertising restrictions in an attempt to hide the rising inflation from which the country has suffered (Pisani, 2013). The United States expressed its disapproval regarding the measure, stating that the measure is a violation to the freedom of speech and especially affects the socalled "commercial speech" (Pisani, 2013). According to Jose Fernandez, current United States Assistant Secretary of State for Economic, Energy, and Business Affairs, Obama's government will evaluate the impact this restriction may have on American companies operating in Argentina, which could result in further actions from the American government to guarantee the regular operations of the American companies in Argentina (Pisani, 2013).

\section{Advertising: A Mirror of Societal Changes}

The unprecedented economic change in Argentina provides a unique lens showing how economic changes manifest advertising practice. Indeed, economic changes are important forces to shape advertising practices (Ahn et. al, 2011). A number of studies investigated how societal changes manifest themselves in advertising. Since Carey (1960) provided a framework 
explaining the shifts toward capitalism in Hong Kong, several researchers have supported through their studies that advertising appeals are adjusted to fit societal shifts (e.g., Ahn, Song, \& Sung, 2011; An 2003; Wong, 2000).

Potter (1954) suggested that advertising is a modern institution that reacts to the economic order, and since the content of an ad reflects the preferences of the consumers, advertising then becomes a window through which the society can be examined and explained. Since then, studies by Pollay (1985), Hanson (1974), Coleman (1998), An (2003), Alozie (2005), Kim, Han, and Yoon (2010), among others, have supported this claim in a variety of contexts, such as the effects of the Great Depression in advertising.

As advertising is part of the changing social, cultural and business environment, its success depends on the ability of the advertisers to predict and react to a changing society. Therefore, socio-economic and political conditions influence the society, and thus, the contents of ads (An, 2003). Given this theoretical perspective, Seldon (1963) found that in the 1920s, ads were likely to depict and promote an imagery related to prosperity, which was taken aback by the market collapse of 1929. According to An (2003), the look and content of advertising in the early 1930s were affected by economic and professional concerns.

In addition to these findings, Ahn et al. (2011) conducted a study to examine whether, and to what extent, economic circumstances influence and shape advertising, specifically financial services ads in magazines. In order to do so, 1,488 ads corresponding to the years between 2005 and 2009 were analyzed to examine if the strategic and tactical appeals had changed in the wake of the 2008-2009 economic crises. Their results showed that "the economic recession is a fertile period that determines how the picture of our society looks like" (Ahn et al., 2011, p. 239). It was suggested that during that time, the ads became more rational and less 
emotional, which is a valuable indication that an economic downturn can have a major impact on advertising.

In sum, the situation seems to indicate that the luxury brands operating in Argentina should undertake changes in their communication strategies to better fit and satisfy the revolutionized and restricted market. A slew of luxury goods retailers are leaving Argentina in response to the import barriers and the impossibility to acquire foreign currencies. After finding it impossible to restock their shelves, Ralph Lauren, Louis Vuitton, and Cartier announced in September 2012 the temporary closure of their stores in the country (Helft, 2012). On the other

hand, a strategic reaction by the domestic brands should also be expected considering the lack of competition.

\section{Advertising Psychology: Appeals, Strategies, and Tone in Luxury Brand Advertising}

This study investigates how luxury brand companies manifest concerns about the economy in the ways that they appeal to consumers via advertising. According to Lee, Chung, and Paik (2011), the basic role of advertising in capitalism "involves the provision of market information by interested sellers and buyers with the consequence of facilitating consumers' judgment and decision making” (p. 246). Investigating appeals (the themes and values emphasized through advertising) may provide a useful framework from which to illuminate changes in the wake of economic change because the appeals are deeply rooted in societal factors (An, 2003; Ahn et al., 2011).

While advertising literature has identified several different types of advertising appeals, there is a consensus among scholars that appeals can be broadly classified into two types: rational and emotional (Leonidou \& Leonidou, 2009; Preston, 1968; Huertas, Zuniga, \& 
Campomar, 2008; Albers-Millers \& Royne Stafford, 1999). Rational appeals are framed upon logical approaches such as comparative advertising and open- and close-ended comparison, whereas emotional appeals include feeling-evoked messages such as those of belonging, guilt, and fear (Kotler \& Armstrong, 2008).

In a different line, Snyder and DeBono (1985) conducted a study in order to understand the use of advertising appeals based on behavioral constructs. The authors suggested that according to the individual's position toward other agents in society, the person could be broadly classified into two categories: high self-monitoring individuals (people who tailor their behavior to fit social considerations) and low self-monitoring individuals (who guide their behavioral choices on the basis of information and inner feelings and attitudes). Advertisers then tailor their ads accordingly to effectively approach each of these consumers by using two different appeals: image-oriented and function-oriented.

Further, Snyder and DeBono (1985) provided a framework through which it becomes possible to identify the use of each of the aforementioned appeals. On one hand, image-oriented appeals are more likely to incorporate images that allow high self-monitoring individuals to perceive that a given product has the potential to be used to create or enhance their image in society. Consequently, ads normally convey sophistication promises and the sense of happiness and self-fulfillment, among other emotional-oriented appeals. On the other hand, functionoriented appeals feature information about product quality, performance, design, and durability. Subsequently, the ads maximize the consistency between the individual's specific preferences with the evaluative information available to him/her, making use of the person's rationale. Thus, it is possible to find consistencies between the theoretical constructs behind the image-oriented and emotional appeals, as well as the function-oriented and rational appeals. 
In addition to the function-oriented vs. image-oriented appeals, advertising strategies and commercial tone and atmosphere (Frazer, Sheehan, \& Patti, 2002) provide a useful framework to investigate changes in luxury brand advertising. While marketing in the luxury goods sector relies heavily on traditional market concepts (Atwal \&Williams, 2009), luxury communications specialists need to face the challenges of a connected world that changes our environment rapidly (Kapferer \& Bastien, 2009). More traditional techniques such as brand positioning, consumeroriented companies, and segmented advertising fall short in the luxury marketing practices because of the specificities of the luxury goods: "luxury is a culture, which means that you have to understand it to be able to practice it with flair and spontaneity" (Kapferer \& Bastien, 2009, p. 313).

When it comes to luxury brands, it is necessary to internalize that these brands are not the result of a market need, but are the product of a brand's willingness to do something out of the ordinary, such as Yves Saint Laurent and Chanel, among others. Thus, to broaden our understanding of luxury brand advertising, the current study borrows Frazer et al.’s (2002) construct of appeals and commercial tones of advertising. Their study found that effective advertisements in Australia and the United States were similar in terms of selling propositions, tone, and positive versus negative appeals. On the other hand, the campaigns differed in their creative strategy, rational versus emotional appeals, and the presence of a brand-differentiating message. The authors then suggest that the differences in advertising were a consequence of the differences in the marketplace and cultural environment.

Furthermore, behaviorist theories suggest that people receive vicarious reinforcement of a behavior by observing a model being rewarded for a specific action (Sung \& Hennink-Kaminski, 2008). If taking into account that repeated advertising appeals and strategies used in advertising 
reinforce positive beliefs associated with a specific product and that luxury ads tend to portray the individuals as glamorous, popular, attractive, successful, and influential, it is expected to find this kind of positive imagery in most luxury ads.

\section{Code-Switching and Luxury Brand Advertising}

Advertisers often use foreign languages in their communications in an attempt to influence the audience's perception of the product (Bishop \& Peterson, 2011). The use of two (or more) languages in the same advertisement, called "code switching," has been studied by many researchers (e.g., Bhatia, 1992; Piller, 2000; Carrol \& Luna, 2011).

Several studies demonstrated that the use of a foreign language in ads can evoke different feelings and reactions from consumers (Gerrisen et al., 2007; Krishna \& Ahluwalia, 2008; Puntoni, De Langhe, \& Van Osselaer, 2008; Takashi, 1990). For example, Italian brand names or words inserted into an advertisement in the United States can make the product appear more "chic," whereas German brand names or words give the perception of quality and reliability (LeClerc, Schmitt, \& Dube, 1992). Hornikx, Van Meurs, and Starren (2007) also argued that the use of French language in advertising is associated with beauty and elegance, while German evokes reliability and technicality. The use of English within an ad in non-English speaking countries is seen as a more sophisticated way of conveying the message, while provoking associations with the ideas of globalism, modernity, and prestige (Hornikx et al., 2010).

Oftentimes, a foreign language can be used as a symbol and the meanings of words do not matter (Hornikx et al., 2010). As Piller (2000) noted, even if consumers could not understand the message being conveyed in the foreign language, they could recognize the language and activate the stereotypes they have about that culture. 
Noriega and Blair (2008) also suggest that advertisements presented in the receiver's native language are more likely to evoke associations related to family, friends, home, or homeland than ads in other languages, while the second-language contexts are likely to evoke other feelings. Thus, it is meaningful whether the code-switching technique has been used in local luxury brands advertising to attract consumers in Argentina in the wake of import restriction.

In addition, investigating code-switching practices in advertising in Argentina can shed light on the advertising literature in Latin American. While decades of code-switching advertising research has been conducted on the use of the English language, not much attention has been paid to the perception of European languages in advertisements in Latin America.

\section{The Role of Human Model Ethnicity in Luxury Brand Advertising}

Among the many visual components of an ad, the people featured in it influence the consumer's perception. Extensive research has been conducted to understand how matching model and consumer ethnicity increase ad effectiveness (Knobloch-Westerwick \& Coates, 2006). For example, Ryu, Park, and Feick (2006) argued that endorsers with similar ethnicity to the audience exert strong influences on audience responses for hedonic products. If it is taken into account that luxury goods are normally used for hedonic purposes, hence hedonic products, it is then presumed that luxury brands advertising in Argentina will use a model with a similar ethnic background.

Furthermore, Sung and Hennink-Kaminski (2008) state that although advertising visual imagery may expose consumers to informative messages about the product, it also provides peripheral cues, such as photos and human model depictions and characteristics, that attract 
attention and/or facilitate identification with the people depicted. According to the social learning theory, when people are exposed to symbolic media, such as advertising, it serves as a powerful modeling influence. Previous research shows that media effects increase when ads depict models with whom consumers identify, and this is normally conveyed visually (Sung \& Hennink-Kaminski, 2008).

Bearing in mind that $97 \%$ of the Argentine population is white and of European descent (CIA Factbook, 2012) and that Argentines have an obsession of hiding and denying any ties to races other than white (Andrews, 1980), it is possible to assume the luxury advertisements in Argentina will depict European-looking-people to evoke a more sophisticated and cosmopolitan feeling among their consumers. Thus, it would be meaningful to investigate whether or not advertisements will portray other ethnicities in wake of restrictions to evoke a more inclusive feeling in wake of the restrictions.

\section{Visual Cues In Advertising: The Power of Images}

Among the many research trends embraced by advertising scholars, one of the most recurring study venues has to do with whether ads are dominated by image information as well as the general layout of promotional material (Dilley, 1986; Johnston \& Tieh, 1983). Research has suggested that audiences process visuals faster, more easily, and more efficiently than written text (Barry, 1997; Blair, 1996; Graber, 1996; Messaris, 1997; Paivio, 1979; Schill, 2012). Given the importance of examining visual cues in addition to verbal statements of ads, the current study incorporates several verbal cues used in luxury ads into the investigation.

First, photographic images of backgrounds have a considerable visual impact on consumers (Dewar \& Davis, 2005) because photos are interpreted through cultural lenses. When 
a picture is used as advertising background, the knowledge and experiences associated with that image exhort strong influences on the receiver. Davis (2004) and Davis and Khare (2002) studied potential travelers' perceptions of photographic travel images to distinguish specific market niches for travel preferences for purposes of tourism product development. By extension, if a luxury product is depicted in front of a seemingly sophisticated destination, it could be expected for the viewer to develop an association between the feelings evoked by the destination and the product characteristics.

Second, in the study conducted by Dewar and Davis (2005), the authors suggest that there is a strong positive interest among picture viewers in heritage architecture, adventure and exotic places, and natural areas showing vistas. The authors imply that there is a stronger interest for foreign and exotic images, causing a higher impact on the decoder. Thus, it is expected that the majority of luxury advertisements will depict high-impact images to evoke the sense of exclusivity, rarity, and uniqueness normally associated with the nature of luxury products.

Third, advertising literature suggests that there is a relationship between vertical visual cues in an ad and the consumer's luxury impressions of the product (Van Rompay, de Vries, Bontekoe, \& Dijkstra, 2012). Given that in the western society it is customary to observe and perceive the different types of power in terms of verticality (e.g., high class, uptown, upscale), there is a common association between power and the upward notions. Van Rompay, et al. (2012) suggested that an upward camera angle triggers a perception that the product is more luxurious, compared to a downward angle. Furthermore, a vertical-oriented background (e.g., the top of the Eiffel Tower, the Empire State Building) triggered perceptions of the product as more luxurious compared to a horizontally oriented background. In sum, the authors' findings support the "verticality-luxury" relationship by demonstrating that effects of background orientation are 
mediated by perceived product luxury, and by showing that given that situation consumers are willing to pay a premium price.

Finally, previous research suggests that the physical characteristics of the ads have a direct effect on ad exposure (Krugman \& King, 2001). In a study investigating tobacco advertisement changes after a series of policies implementation, Sung and Hennink-Kaminski (2008) add to the findings by Krugman et al. by saying that the use of cover positions, color, and photography, rather than artwork, varied reflecting the changes in market rules. Thus, following the results of the tobacco studies, it could be expected that pictures, rather than words, will become the dominant method for advertising to luxury consumers.

In sum, several visual cues and techniques used in luxury advertising are considered to explore how advertisers use visual information in luxury ads in the wake of the import and currency restrictions in Argentina. Thus, the use of photography, background setting, camera angle, and the physical characteristics of ads are considered in this study.

\section{RESEARCH QUESTIONS}

This study focuses on magazine ads to illustrate changes in the luxury market in Argentina because magazines are the primary advertising medium through which product information is disseminated in the luxury market (Fitzgerald, 2012; Doran, 2012). In addition, persuasive appeals and marketing strategies are notably depicted in magazine ads (Ahn et al., 2011). Based upon the aforementioned theoretical frameworks in advertising appeals and persuasive communication, the following six research questions were developed to guide the current study: 
RQ 1: Have there been any changes in the frequency of advertisement placement in fashion magazines in the wake of the import and currency restrictions in Argentina?

RQ 2: Have there been any changes in the appeals of luxury brands advertisement in fashion magazines in the wake of the import and currency restrictions in Argentina? More specifically, have there been any changes in a) function-oriented vs. image-oriented advertising and b) the use of emotions in the ad? If emotions were used in the ad, c) what are the most frequent emotions depicted in fashion magazines after the import and currency restrictions?

RQ 3: Have there been any changes in creative strategies and commercial tones of luxury brands advertisements in fashion magazines in the wake of the import and currency restrictions in Argentina?

RQ 4: Have there been any changes in code switching (i.e., mixing languages within a sentence) used in luxury brand advertising in magazines after the implementation of the import and currency restrictions in Argentina?

RQ 5: Have there been any changes in the ethnicity of human models in luxury brand advertising in magazines after the implementation of the import and currency restrictions in Argentina? 
RQ 6: Have there been any changes in the advertisement visual cues implemented by luxury brands in fashion magazines in the wake of the import and currency restrictions in Argentina? More specifically, have there been any changes in a) types of ad illustrations,

b) background setting, and c) camera angles in fashion magazines in the wake of the import and currency restrictions in Argentina?

\section{METHOD}

To answer the research questions, a content analysis of luxury brands advertisements placed in one of the most popular fashion magazines in Argentina was conducted as an exploratory approach. Because of the nature of the research questions, content analysis appears to be a useful tool to investigate the phenomenon. Content analysis is a strictly controlled methodology through which text, images, or symbolic material is analyzed step-by-step to describe variables, the relationships between them, and to reach conclusions about the content's context and consumption (Krippendorf, 2004; Marying, 2000). In addition, "it is not limited as to the type of messages that may be analyzed, nor as to the types of constructs that might be measured" (Neuendorf, 2002, p. 10). Neuendorf and Skalski (2010) also indicated that content analysis is one of the most scientific tools to describe recorded human communication.

Numerous studies support the use of content analysis as a way to provide valuable cultural and historical inferences through the analysis of the samples (Berg, 2001; Bryman, 2008; Krippendorf, 2004; Kritski, 2012; Webber, 1990). In addition, content analysis has been successfully used to analyze the effects of socio-economic happenings on advertising (An, 2003; Ahn et al., 2011; Lee, Chung \& Paik, 2011; Abernethy \& Franke, 1996; Pollay, 1986). 
The controversy surrounding content analysis as a method has to do with the inferences and conclusions obtained from the data (Hansen et al., 1998). Thus, to achieve high validity, the coding scheme of the study remained consistent across all ads fulfilling the reliability criteria suggested by Riffe, Lacy, and Fico (1998).

\section{Sample}

The unit of analysis for this study is the individual magazine ad, mirroring similar content analysis research on the effects of societal changes in advertising. A sample of 398 unique advertisements was drawn from an Argentine fashion magazine over the calendar years 2009, 2010, 2011, and 2012. Para Ti Colecciones (PTC) was chosen for analysis.

The selection of this magazine for the current study is considered appropriate for a number of reasons. First, PTC is one of the first fashion magazines published in the world (with its first appearance on May 16, 1922) and is considered a reference when it comes to beauty and fashion in Argentina ("Para Tí," n.d.). Second, the magazine circulates in the whole Argentine territory, with an approximate circulation of 48,000 and a readership of 185,000 ("Para Tí," n.d.). Third, it contains a large number of luxury brand advertisements targeting luxury consumers. According to Total Medios, a Latin American media website that provides information about the advertising industry, the PTC readers are Argentine women between 18 and 60 years old.

The time frame selected for study is from January 2009 to December 2012. To conduct the study, 2009 and 2010 are identified for this study as the pre-restrictions era and 2011 and 2012 are identified as the restrictions era. This is because in February 2011 the Industry Secretary in Argentina passed the Resolution 45/2011, which regulates the imports through a system of non-automatic licenses indefinitely. 


\section{Coding Scheme}

To develop a relevant and comprehensive coding scheme for this study, existing coding schemes pertinent to the research questions were adapted. These schemes have been employed in previous advertising content analysis studies.

Frequency. Previous research has used content analysis to explore the frequency of advertisement placement in the media to determine the communicative campaigns' effects on a specific population. While most studies analyze the repetition (or absence) of certain ad features (e.g. psychological effects, product type, contained information, and conformity), the nature of the research questions of this study limits the analysis to the presence or absence of advertisement placement in fashion magazines to determine whether the restrictions in Argentina have potentially influenced the advertising industry.

Advertising Appeals. Following Snyder and DeBono’s (1985) propositions on advertising, it is considered whether or not the ads convey information about the images the consumer may acquire and project by using a particular product (image-oriented) or messages about a product's quality (function-oriented) that may be interpreted by consumers in terms of their underlying attitudes, values, and other evaluative reactions. In addition, it is analyzed whether the ad used a certain emotion as the basis of the message or not. The emotions were broadly classified in four groups: cheerful, quiescent, dejection, and agitation (Wilcox, Kim \& Sen, 2009). Each of these items is presented in Appendix 1.

Advertising creative strategies and tones. RQ 3 concerns changes in advertising creative strategies upon the restrictions implementation in Argentina. Following the findings by Ahn et al. (2011), which suggest that advertising appeals vary in wake of specific economic situations, and by implementing the model proposed by Frazer, Sheehan, and Patti (2002), the categories to 
be tested in the ads intend to identify whether, and to what extent, the advertisers have shifted their strategies to captivate the reader through a specific tactic. As a result, 12 categories including product performance, economical value, sexual images of products, and symbolic meaning were added. Each of these items is presented in Appendix 1.

Language. Taking into account that several studies have demonstrated that the use of a foreign language in ads (code-switching) can evoke different feelings and reactions from consumers (Gerrisen et al., 2007; Puntoni, De Langhe \& Van Osselaer, 2008; Krishna \& Ahluwalia, 2008; Takashi, 1990), the ads were examined to determine whether foreign languages (such as Italian, English, or French) were present in the ads.

Human Model Ethnicity. As mentioned, Argentines often deny any ethnical roots other than European, and this can often lead to the assumption that there are not any additional races present in the country other than the white majority (Andrews, 1980). Despite this view, some advertising agencies have successfully included models representing the country's minorities in their ads (e.g, Movistar Copa América). It then becomes of interest to know whether the luxury brands will advertise in a different way upon the wake of imports and currency restrictions. Thus, following the race definitions provided by the C.I.A. Factbook (2005), and based on the previous study by Sung and Hennink-Kaminski (2008), the ethnicity of human models in advertising was examined. The races listed are white, mestizo, Amerindian, and "other".

Visual cues. Previous research indicates that in light of a change in public policies, the use of ad illustration and artwork varies. Following the findings of Sung and Hennink-Kaminski (2008), which looked at ad illustration in addition to the effects of camera angle (i.e., verticality cues) in advertising (van Rompay et al., 2012), the ads were examined to determine whether ad illustration and camera angles of ads underwent changes. Furthermore, advertisement-setting 
particularities were examined by adding two categories: geographical and physical setting of the ad (McArthur \& Resko, 1975) and physical characteristics of ads. Measured visual cue items are described in Appendix 1.

\section{RESULTS}

\section{Inter-coder Reliability}

Two bilingual coders who are fluent in Spanish and English, as well as blind to the objective of the study, coded ads using a codebook developed for the study. All coders were trained through a series of intensive sessions to ensure understanding of coding instructions and a consistent, reliable coding process. During training sessions, coders worked together and analyzed ten ads as a pilot study. These ads were not included in the final sample. Any points of disagreement between coders were reexamined and discussed and, after reaching an agreement on each coding item $(I r<0.70)$, each coder coded all sample ads.

To validate reliability between coders, Perreault and Leigh's Ir was used. This index is considered to be better than percentage agreement and Cohen's K, and is particularly suited for nominal data with mutually exclusive categories (Avery and Ferraro, 2000; Cho and Cheon, 2005). Ten percent of sample materials are usually used to obtain acceptable inter-coder reliability (Lee et al., 2007); thus, for this study, 12\% (50 ads) of the sample was used to calculate the PI index. Results of the inter-coder reliability test were high, with the PL index ranging from .90 to 1.00-higher than the acceptable point of .70 (Perreault \& Leigh, 1989). Table 1 summarizes the operational definitions and reliability of each variable. 
Table 1: Operational definitions and intercoder reliability

Operationalization

Advertised luxury brand- Country of Origin

Ir

- International luxury brand

- Argentine luxury brand

Appeals

- Function-oriented appeal: emphasizes the consumers' practical, functional, and utilitarian need, such as quality and reliability of products

- Image oriented appeal: emphasizes image-related aspects of products such as a particular image of a brand in a society or a symbol of a society

Use of the emotions

Depicted emotions

0.98

- Cheerful: happiness, elation, joy, excitement, delight, gladness

- Quiescent emotions: calmness, placidness, restfulness, peacefulness, relief

- Dejection: sadness, regret, disappointment, depression, shame, blame, worthless.

- Agitation: stress, tension, anxiety.

Creative strategies and tones:

- Product performance: shows or explains how the product functions

- Utilitarian need: explains the effectiveness of products

- Ingredients of products: explicit mention of a product's ingredient

- Economical value: addresses the consumer's economic benefits

- Self-esteem/self-images of products usage: being different from others

- Accomplishment and achievement: Reflection of self fulfillment

- Sexual images of products: Sexually attractive or exciting images

- Modern/contemporary looks: new, innovative, improved products.

- Technological aspects: caused by technical advances in production methods

- Safety/Secured image of products: stable and reliable products.

- Relaxed/comfortable: being laid back images of products.

- Symbolic meaning: impressions of the product in a society.

Code switching: Use of two or more languages to address the product

Human model ethnicity:

- White: a person of European descent

- Mestizo: a person of mixed races

- Amerindian: any member of the peoples living in North or South America before the Europeans arrived

- Other: any other known races such as Asian, African American, etc. 


\section{Visual cues}

I. Illustration: whether the ad is the product of artistic work or not

- Photography

- Artwork

- Combination of the two

II. Advertisement setting / location:

- Local theme: the depicted background recreates the Argentine culture, landscape or architecture.

- International theme: the background depicted clearly denotes an international setting, such as the Eiffel Tower.

- Studio setting: the subjects pose in front of an artificial background, such as cloths or are superimposed on a background impossible to capture through a real-life photography session, such as the space.

- Illustrated background: the background is the result of graphic design

- No background: the models are superimposed over a solid background such as all white or black.

- Other: any other situation not contemplated in the above-mentioned options.

III. Camera angle:

- Vertical camera angle of the background in the ad: vertical objects are prominent in the background, such as the Eiffel Tower or the Empire State Building.

- Horizontal camera angle of the background in the ad: the background is parallel to the plane of the horizon.

- Horizontal camera angle of the product: the product lies horizontally, in line with the horizon.

- Vertical camera angle of the product: the product lies in a direction normally associated with top and bottom.

Overall

Perreault and Leigh (Ir) Index

\section{Frequency}

The first research question asked whether there was a change in ad placement frequency before and after the restrictions implementation. Among 398 unduplicated PTC ads, 198 ads were identified in the pre-recession era (2009-2010), and 200 were placed in the recession era (2011-2012). As shown in Table 2, the frequency of ads per year did not suffer significant variations during the recession era. Among various product categories of luxury brands, fashion (89.4\%) appeared the most frequently across the two eras, followed by accessories $(3.8 \%)$ and 
perfumes and cosmetics $(3.8 \%)$, watches $(2.5 \%)$, and automobiles $(0.5 \%)$. There was no significant variation between the two eras with regards to product categories. Table 2 summarizes the frequency and percentage of luxury ads.

Table 2: Frequency and percentage of unique luxury ads on PTC

\begin{tabular}{cccccc}
\hline & \multicolumn{2}{c}{ Pre-restrictions $(\mathrm{N}=198)$} & \multicolumn{2}{c}{ Restrictions $(\mathrm{N}=200)$} & Total N=398 \\
\cline { 2 - 5 } & 2009 & 2010 & 2011 & 2012 & \\
\cline { 2 - 4 } $\begin{array}{c}\text { International } \\
\text { brand }\end{array}$ & $27(27.6 \%)$ & $19(19.0 \%)$ & $23(21.9 \%)$ & $17(17.9 \%)$ & $86(21.6 \%)$ \\
Argentine & $71(72.4 \%)$ & $81(81.0 \%)$ & $82(78.1 \%)$ & $78(82.1 \%)$ & $312(78.4 \%)$ \\
brand & & & & \\
Fashion & $90(91.8 \%)$ & $88(90.7 \%)$ & $91(86.7 \%)$ & $87(90.6 \%)$ & $356(89.0 \%)$ \\
Perfumes \& & $4(4.08 \%)$ & $2(2.1 \%)$ & $4(3.8 \%)$ & $5(5.2 \%)$ & $15(3.8 \%)$ \\
Cosmetics & & & & \\
Watches & $0(0 \%)$ & $5(5.1 \%)$ & $4(3.8 \%)$ & $1(1.0 \%)$ & $10(2.5 \%)$ \\
Jewelry \& & $4(4.08 \%)$ & $4(4.1 \%)$ & $5(4.8 \%)$ & $2(2.1 \%)$ & $15(3.8 \%)$ \\
Accessories & & & & \\
Automobiles & $0(0 \%)$ & $1(1.0 \%)$ & $1(1.0 \%)$ & $0(0 \%)$ & $2(0.5 \%)$ \\
Wines \& & $0(0 \%)$ & $0(0 \%)$ & $0(0 \%)$ & $0(0 \%)$ & $0(0 \%)$ \\
$\begin{array}{c}\text { Spirits } \\
\text { Others }\end{array}$ & $0(0 \%)$ & $0(0 \%)$ & $0(0 \%)$ & $0(0 \%)$ & $0(0 \%)$ \\
\hline
\end{tabular}

\section{Advertising appeals}

The second research question concerned changes in specific luxury brands appeals over the restrictions implementation. While the chi-square analysis revealed that there was no significant change in function-oriented vs. image-oriented advertising, there was a significant decrease in the ads using emotions $\left(\chi_{1}^{2}=28.17, p<.001\right)$, decreasing from $91.46 \%$ during the prerestrictions era to $70.5 \%$ in the restrictions era. The ads seem to be less likely to depict emotions in wake of the adverse economic conditions. Among four categories of emotions, two emotions showed significant variations: cheerful and quiescent emotions. There was a significant decrease in the use of cheerful emotions (64.1\% vs. $45.5 \%)$ during the restrictions era $\left(\chi^{2}{ }_{1}=13.95, p<\right.$. 
001). In addition, there was a significant decrease in the use of quiescent emotions during the restrictions era $\left(62.6 \%\right.$ vs. $\left.19.5 \% ; \chi^{2}{ }_{1}=76.52, p<.001\right)$. The use of dejection $(p=.09)$ and agitation $(p=.60)$ did not result in significant changes. Table 3 shows the results of advertising appeals.

Table 3: Advertising appeals in PTC ads

\begin{tabular}{|c|c|c|c|c|c|c|}
\hline \multirow{2}{*}{\multicolumn{2}{|c|}{$\begin{array}{c}\begin{array}{c}\text { Total } \\
(N=398)\end{array} \\
\frac{N(\%)}{\text { Function-oriented versus i }}\end{array}$}} & $\begin{array}{c}\text { Pre-restrictions } \\
(N=198)\end{array}$ & $\begin{array}{c}\text { Restrictions } \\
(N=199)\end{array}$ & $\chi^{2}$ & $p$ & $d f$ \\
\hline & & \multicolumn{5}{|c|}{ Function-oriented versus image-oriented ${ }^{a}$} \\
\hline Function & & $11(5.6 \%)$ & $13(6.5 \%)$ & .15 & .69 & 1 \\
\hline Image & & $190(96 \%)$ & $197(98.5 \%)$ & 2.38 & .12 & 1 \\
\hline \multicolumn{4}{|c|}{ Presence of emotions $^{b}$} & 28.17 & .00 & \\
\hline Yes & & $181(91.4 \%)$ & $141(70.5 \%)$ & & & 1 \\
\hline No & & $17(8.6 \%)$ & $59(29.5 \%)$ & & & 1 \\
\hline \multicolumn{7}{|c|}{ Emotions depicted ${ }^{a}$} \\
\hline Cheerful & & $127(64.1 \%)$ & $91(45.5 \%)$ & 13.95 & .00 & 1 \\
\hline Quiescent & & $124(62.6 \%)$ & $39(19.5 \%)$ & 76.52 & .00 & 1 \\
\hline Dejection & & $5(2.5 \%)$ & $1(0.5 \%)$ & 2.74 & .09 & 1 \\
\hline Agitation & & $22(11.1 \%)$ & $19(9.5 \%)$ & .26 & .60 & 1 \\
\hline
\end{tabular}

${ }^{\mathrm{a}}$ Multiple appeals could be coded per ad

${ }^{\mathrm{b}}$ Only one option could be coded per ad

\section{Creative strategies and tones}

To answer the third research question, a chi-square analysis of the creative strategies and tones used in luxury brand advertising was conducted. The results, shown in table 4, revealed that 13 out of 14 strategies and tones significantly changed. For example, self-esteem was found to be the most significant change, decreasing from $78.8 \%$ to $39 \%$ between two eras $\left(\chi_{1}^{2}=65.01, p\right.$ $<.001)$. Likewise, modern appeals decreased from $49.5 \%$ to $13 \%\left(\chi^{2}{ }_{1}=61.78, p<.001\right)$, and accomplishment appeals from $62.1 \%$ to $34 \%\left(\chi_{1}^{2}=33.15, p<.001\right)$. Appeals related to sexual images also decreased from $49 \%$ to $25.5 \%\left(\chi^{2}{ }_{1}=23.5, p<.001\right)$, and safety appeals decreased 
from $11.10 \%$ to $.50 \%\left(\chi_{1}^{2}=20.57, p<.001\right)$. Symbolic meaning associated appeals decreased from $58.1 \%$ to $36.5 \%\left(\chi_{1}^{2}=20.06, p<.001\right)$, and social approval appeals decreased from $56.6 \%$ to $36.5 \%\left(\chi_{1}^{2}=16.1, p<.001\right)$. In the same line, the use of relaxed appeals shrank from $61.6 \%$ to $47.5 \%\left(\chi_{1}^{2}=7.99, p<.01\right)$. In smaller proportions, the use of more product-specific appeals also showed a decrease in use. Product performance appeals such as ingredient-oriented decreased from $1.5 \%$ to $0 \%\left(\chi_{1}^{2}=.86, p<.4\right)$, economical value shrank from $11.1 \%$ to $1.5 \%\left(\chi_{1}^{2}=15.61, p\right.$ $<.001)$, and technological appeals were reduced from $4 \%$ to $0 \%\left(\chi_{1}^{2}=8.24, p<.001\right)$.

Among 13 changed appeals, only three appeals showed increases, including product performance $\left(3.6 \%\right.$ vs. $\left.5.5 \% ; \chi^{2}=.86, p<.4\right)$, utilitarian needs $\left(2 \%\right.$ vs. $\left.7 \% ; \chi^{2}{ }_{1}=5.71, p<.05\right)$ and trendy appeals $\left(31.3 \%\right.$ vs. $\left.48.5 \% ; \chi^{2}{ }_{7}=21.4, p<.001\right)$.

Table 4: Presence of strategies and tones in PTC ads

\begin{tabular}{lccccc}
\hline & $\begin{array}{c}\text { Pre-restrictions } \\
(N=198)\end{array}$ & $\begin{array}{c}\text { Restrictions } \\
(N=199)\end{array}$ & $\chi^{2}$ & $P$ & $d f$ \\
\cline { 2 - 3 } & $N(\%)$ & $N(\%)$ & & & \\
\hline Product performance & $7(3.6 \%)$ & $11(5.5 \%)$ & .86 & .35 & 1 \\
Utilitarian need & $4(2 \%)$ & $14(7 \%)$ & 5.71 & .01 & 1 \\
Ingredient & $3(1.5 \%)$ & $0(0 \%)$ & 3.05 & .08 & 1 \\
Economical value & $22(11.1 \%)$ & $3(1.5 \%)$ & 15.61 & .00 & 1 \\
Self-esteem & $156(78.8 \%)$ & $78(39 \%)$ & 65.01 & .00 & 1 \\
Accomplishment & $123(62.1 \%)$ & $68(34 \%)$ & 33.15 & .00 & 1 \\
Sexual images & $97(49 \%)$ & $51(25.5 \%)$ & 23.5 & .00 & 1 \\
Modern & $98(49.5 \%)$ & $26(13.0 \%)$ & 61.78 & .00 & 1 \\
Technological & $8(4 \%)$ & $0(0 \%)$ & 8.24 & .00 & 1 \\
Safety & $22(11.1 \%)$ & $1(0.5 \%)$ & 20.57 & .00 & 1 \\
Relaxed & $122(61.6 \%)$ & $95(47.5 \%)$ & 7.99 & .01 & 1 \\
Symbolic meaning & $115(58.1 \%)$ & $73(36.5 \%)$ & 20.06 & .00 & 1 \\
Social approval & $112(56.6 \%)$ & $73(36.5 \%)$ & 16.1 & .00 & 1 \\
Trendy & $62(31.3 \%)$ & $97(48.5 \%)$ & 21.4 & .00 & 7 \\
\hline
\end{tabular}

\section{Code-switching}

The fourth research question concerned changes in the use of code switching between the two eras. The chi-square analysis, as shown in table 5, revealed that there was no significant variation $\left(\chi_{1}^{2}=.70, p=.40\right)$ among the ads. Among various language categories, Spanish $(41.5 \%)$ 
appeared the most frequently across the two eras, followed by absence of verbal messages (34.7\%), English (20.9\%), and French (3\%). Interestingly, the use of the English language decreased in use during the restrictions era $(17 \%)$ in comparison to the pre-restrictions era $(24.7 \%)$.

Table 5: Code-switching in PTC ads

\begin{tabular}{|c|c|c|c|c|c|c|}
\hline & $\begin{array}{c}\text { Pre-restrictions } \\
(N=198)\end{array}$ & $\begin{array}{l}\text { Restrictions } \\
(N=199)\end{array}$ & $\begin{array}{c}\text { Total } \\
(N=398)\end{array}$ & $\chi^{2}$ & $p$ & $d f$ \\
\hline & $N(\%)$ & $N(\%)$ & & & & \\
\hline Code-switching & $24(12.1 \%)$ & $30(15 \%)$ & & .70 & .40 & 1 \\
\hline Languages used & & & & 4.6 & .20 & 3 \\
\hline Spanish & $80(40.4 \%)$ & $85(42.5 \%)$ & $165(41.5 \%)$ & & & \\
\hline French & $7(3.5 \%)$ & $5(2.5 \%)$ & $12(3 \%)$ & & & \\
\hline English & $49(24.7 \%)$ & $34(17 \%)$ & $83(20.9 \%)$ & & & \\
\hline No verbal lang. & $62(31.3 \%)$ & $76(38 \%)$ & $138(34.7 \%)$ & & & \\
\hline Total & $198(99.9 \%)$ & $200(100 \%)$ & $398(100 \%)$ & & & \\
\hline
\end{tabular}

\section{Model ethnicity}

Regarding the fifth research question (i.e., changes in the ethnicity of human model depicted), the results did not indicate a significant change in the wake of the restrictions $\left(\chi_{1}^{2}=1.18, p=.17\right)$. It is important to note that across the two eras, $98.7 \%$ of the human models depicted were white, while only $1.3 \%$ were identified as another race, suggesting that white models are the most frequently depicted in luxury brand advertising. Table 6 summarizes these results.

Table 6: Model ethnicity in PTC ads

\begin{tabular}{lcccccc}
\hline & $\begin{array}{c}\text { Pre-restrictions } \\
(N=198)\end{array}$ & $\begin{array}{c}\text { Restrictions } \\
(N=199)\end{array}$ & $\begin{array}{c}\text { Total } \\
(N=398)\end{array}$ & & $\chi^{2}$ & $p$ \\
\cline { 2 - 4 } & $N(\%)$ & $N(\%)$ & & & & \\
\hline Ethnicity & & & & 1.85 & .17 & 1 \\
White & $194(98 \%)$ & $199(99.5 \%)$ & $393(98.7 \%)$ & & & \\
Other & $4(2 \%)$ & $1(0.5 \%)$ & $5(1.3 \%)$ & & \\
\hline
\end{tabular}




\section{Visual cues}

The sixth research question concerned changes in visual advertising cues over the restrictions. The chi-square analysis indicated a significant difference in the use of ad illustration $\left(\chi_{3}^{2}=29.41, p<.001\right)$, as the use of photography increased from $68.7 \%$ during the pre-restrictions era to $88 \%$ during the restrictions. In contrast, the use of artwork decreased from $15.2 \%$ to $2 \%$ during the restrictions era. In addition, there was a significant difference in the use of a vertical camera angle in luxury brand advertising $\left(\chi_{1}^{2}=10.22, p<.001\right)$ during the restrictions. In wake of the restrictions, $34.5 \%$ of the ads used a vertical background camera angle compared to $20.2 \%$ before the restrictions were implemented. Regarding changes in advertising setting, the results indicated a marginally significant change $\left(\chi_{4}^{2}=9.26 p=.05\right)$ in the wake of the restrictions. Ads recreating indoor settings increased from $34.3 \%$ to $42 \%$, whereas outdoor locations decreased from $57.1 \%$ to $50 \%$ during the restrictions. When it came to the outdoor scenes during the restrictions era, more ads depicted international locations (35\%) than local locations (19\%), while during the pre-restrictions era more ads depicting an outdoor scene were located in a local scene $(31.8 \%)$ than international themes $(22.2 \%)$. Thus, there was a significant change in the geographical location depicted $\left(\chi^{2}{ }_{5}=19.15, p<.001\right)$. Table 7 summarizes these findings.

Table 7: Visual cues in PTC ads

\begin{tabular}{|c|c|c|c|c|c|}
\hline & $\begin{array}{c}\begin{array}{c}\text { Pre-restrictions } \\
(N=198)\end{array} \\
N(\%)\end{array}$ & $\begin{array}{c}\text { Restrictions } \\
(N=199)\end{array}$ & $\chi^{2}$ & $p$ & $d f$ \\
\hline Illustration & & & 29.41 & .00 & 3 \\
\hline Artwork & $30(15.2 \%)$ & $4(2 \%)$ & & & \\
\hline Photography & $136(68.7 \%)$ & $176(88 \%)$ & & & \\
\hline Combination of both & $32(16.2 \%)$ & $18(9 \%)$ & & & \\
\hline Total & $198(100 \%)$ & $198(99 \%)$ & & & \\
\hline Background camera angle & & & 10.22 & .00 & 1 \\
\hline Horizontal & $158(79.8 \%)$ & $131(65.5 \%)$ & & & \\
\hline Vertical & $40(20.2 \%)$ & $69(34.5 \%)$ & & & \\
\hline
\end{tabular}




$\begin{array}{lccccc}\text { Total } & 198(100 \%) & 200(100.1 \%) & & & \\ \text { Setting } & & & 9.26 & .05 & 4 \\ \text { Indoors } & 68(34.3 \%) & 84(42 \%) & & & \\ \text { Outdoors } & 113(57.1 \%) & 100(50 \%) & & \\ \text { Other } & 17(8.6 \%) & 16(8 \%) & & & \\ \text { Total } & 198(100 \%) & 200(100 \%) & & & \\ \text { Location } & & & 19.15 & .00 & 5 \\ \text { Local } & 63(31.8 \%) & 38(19 \%) & & & \\ \text { International } & 44(22.2 \%) & 70(35 \%) & & & \\ \text { Other } & 91(46 \%) & 92(46 \%) & & \\ \text { Total } & 198(100 \%) & 200(100 \%) & & \\ & & & \end{array}$

\section{DISCUSSION}

The purpose of this study was to examine whether, and to what extent, market regulations implemented by the government influence and shape advertising. The findings suggest that changes in public policies indeed affect the advertising industry by transforming the advertising execution.

At the macro level, the study suggests that advertising became less likely to depict strong and clear emotions during the restrictions era. In light of the decreases in feelings associated with happiness, excitement, and gladness (i.e., cheerful emotions) as well as emotions associated with restfulness, peacefulness, and relief (i.e., quiescent emotions) during the restriction era, it is possible to see that this shift can reflect the new living conditions of the Argentine society. The gradual imports and currency restrictions have changed the daily life of millions of higher-class Argentines by prohibiting them from impulsive buying, which would make Argentines more rational and less emotional. Previous studies have also identified historical events that resulted in the decreases in emotional appeals of ads. For example, An (2003) showed that during the wake of the Great Recession, ads in the United States were more likely to depict less joyful emotions than those of the 1920s. 
The results of this study also show that market regulation affects the visual cues of ads, resulting in a preference for the use of photography rather than the use of art in ad illustration during the restrictions era. By using photography, the creative favors a more straightforward approach in the wake of the restrictions than the ornamental, symbolic visuals. The consistent decreases in emotional appeals and decorative techniques suggested by the results of this study suggest that advertisers seem to adopt effective and clear rhetoric and visual techniques to successfully deliver the information about the product to the consumer.

The current study provides additional insights into how advertisers use visual techniques to reflect the societal changes. Specifically, the results indicate a change in the geographical location chosen to display the advertised product, showing evidence of the popularity of international locations as backgrounds of luxury ads during the restrictions era. These findings suggests that in wake of the restrictions, both domestic and international luxury brands are looking to take advantage of the feelings of luxury that the chosen backgrounds evoke. In addition, the result implies that advertisers preferred the use of vertical-oriented (vs. horizontaloriented) backgrounds to advertise the luxury products during the restrictions era. It supports the findings by van Rompay et al. (2012) that the use of a vertical background could increase the consumers' perception of luxuriousness of the products.

A shift in advertising strategies and conveyed messages was also observed within the framework of creative strategies and tones. Among 14 creative strategies, 13 strategies (social approval, accomplishment and achievement, self-esteem, among others) decreased in use, indicating a shift toward more conservative and clean ads during the restriction era. In the same vein, there was a significant increase in addressing the consumer's practical and utilitarian needs 
and the effectiveness of products in the restrictions era. This result indicates that advertising reflects the economic changes in a society.

Interestingly, there was no significant change with regard to the human model characteristics, as the majority of depicted models were found to be white. This fidning can be explained by Andrews' (1981) propositions on the Argentine preference for the European look. Also, no significant change was found in terms of code switching. The results indicated an extended use of the English language throughout the four years of analyzed ads, which could be justified as a consistent and constant attempt to evoke a global feeling through language in luxury brand advertisement, as suggested by Hornikx, Van Meurs, and Starren (2007).

Perhaps one of the most interesting findings in this study is the decreasing pattern in ads encouraging consumers to pay attention to prices and economical value during the restrictions implementation. It is necessary to note that the restrictions are accompanied by an everincreasing inflation rate. These results suggests that luxury brand managers may not want to discourage consumers from making purchases because of advertised value. These findings are in line with those by Ahn et al. (2011), as the authors indicated that there is a significant influence of economic circumstances on advertising messages. They contended that advertisers may assume that potential consumers become vigilant information seekers when there is a chance of economic failure. Thus, the constant changes in the Argentine economy and the continuous decrease in the currency value can justify these changes.

In summary, the results of this study provides empirical evidence that explains how advertisements change in reaction to shifting market circumstances. The changes found in this study suggest that the pattern of appeals turned into a less ornamental, decorative, and emotionaloriented advertising style in wake of the restrictions implementation. The ads in the pre- 
restrictions era used a far wider variety of tactical appeals than those in the restrictions era, reflecting perhaps the restrictive nature of the Argentine market since the Kirchner administration began. The results provide some interesting support for the findings of the studies that demonstrate how changes in economic status serve as considerable in transforming advertising, as again demonstrates that advertising is a mirror of the society.

\section{CONTRIBUTIONS AND IMPLICATIONS}

The purpose of the study was to examine whether, and to what extent, the restrictions implemented by the Argentine government potentially influenced and shaped advertising, especially luxury brands ads in magazines. Theoretically, the results contribute to the field of advertising in several respects. First, the study provides a picture of how advertising undergoes major changes in response to regulatory authority queries and actions. If taking into consideration that advertising mirrors society through its contents and strategies, it is worth analyzing the tactics implemented by the advertisers to try to successfully overcome the socioeconomic downturns in Argentina.

Second, it also extends the Latin American advertisement literature, providing a missing link in the body of advertising research. Argentina, as one of the most prominent countries in the region, has an active and rich advertising industry, and it has been ranked as the fourth most creative country only behind England, the United States, and Brazil (Gunn Report, 2011). In addition, the amount of money spent in advertising in Argentina has been constantly growing since 1998, reaching over US\$ 4.3 billion in 2011 (Argentine Advertising Association, 2011).

Nevertheless, the Latin American luxury market is still an unknown land for many communications professionals, and little research has been conducted about the Argentine 
advertising industry. The robust GDP (Gross Domestic Product) growth in Latin America, in addition to the booming economic growth of the region, represents an opportunity without precedents for the luxury brands. According to Danielle Zito, a luxury consultant at Bain \& Co., the luxury market in Argentina, Brazil, and Mexico are worth US\$5 billion combined, while Chile, Colombia, and Panama follow close behind (Castano, 2011). Needless to say, Argentina has a higher proportionate number of consumers with a disposable income of over $\$ 10,000$ and $\$ 25,000$ (Castano, 2011), making it an appealing market for superluxury brands. Hence, the findings of the study will narrow the gap in luxury brand literature by extending the knowledge about luxury marketing in Argentina.

\section{LIMITATIONS AND FUTURE STUDY}

Although this study provides insights on the effects of economic situations on advertising, it has some limitations that future research could consider. First, it should be taken into account that while a content analysis can provide a significant amount of descriptive information, primary research involving surveys and interviews to agencies and professionals would better help understand the strategies implemented to overcome the economic situation. Thus, future research should adopt various qualitative methods, such as interviews, to extend our understanding of luxury advertising in Argentina.

Second, although this study may provide a depiction of changes in the luxury brands advertising, future research with additional product categories will be of paramount contribution to these findings about whether, and to what extent, the imports and currency restrictions in Argentina have affected the messages placed in the media. For instance, a more representative sample could be achieved by looking at wines and spirits, perfumes, or cars, among others. 
Third, it should also be considered that only magazine advertisements were used for this study. Thus, future research should conduct analyses over various types of media to explore a higher reliability across other media outlets. Particularly, including social networking sites, television and Internet pages, which tailor promotional messages to local markets, would significantly extend our findings.

This research provides important findings for theory and practice, and supports the findings by An (2003), Ahn et al. (2011), and Sung and Hennick-Kaminski (2008) by stating that advertising indeed reacts to changes in market rules by tailoring its content, visual techniques, and commercial tones and strategies. In addition, this study serves as an exploratory research on the advertising industry in Argentina, a market that is growing year after year, and is often ignored by scholars. Yet much remains to be discovered to understand fully the impact of regulatory authority queries and actions on advertising execution. 


\section{REFERENCES}

Aaker, J. L. (1997). Dimensions of Brand Personality. Journal of Marketing Research, 34(3), 347-356.

Abernethy, A, Franke, G. (1996). The information content of advertising: A meta analysis. Journal of Advertising 25(2): 1-17.

An, D. (2003). Content Analysis of Advertising Visuals in the Magazine Advertisements: The Roaring Twenties and the Great Depression. Web Journal of Mass Communication Research, 6(3).

Ahn, H., Song, Y., Sung, Y. (2011). When the Going Gets Tough, Ads Become Straightforward but Multi-Appealed: The Influence of the Recession on Financial Services Advertising Appeals. Journal of Financial Services Marketing, 16(3/4), 230-243.

Alozie, E.C. (2005). Cultural Reflections and the Role of Advertising in the Socioeconomic and National Development of Nigeria. Lewiston, NY: Edwin Mellen Press.

Andrews, G. R. (1980). The afro-argentines of Buenos Aires, 1800-1900. Madison, Wisc: University of Wisconsin Press

Are individual-level and country-level value structures different? testing Hofstede's legacy with the Schwartz value survey. (2010). Journal of Cross-Cultural Psychology, 41(2), 135151.

Atwal, G., \& Williams, A. (2009). Luxury brand marketing - the experience is everything. Journal of Brand Management, 16(5-6), 338-346.

Barry, A. (1997). Visual intelligence: Perception, image, and manipulation in visual communication. Albany, NY: State University of New York Press.

Bishop, M., \& Peterson, M. (2011). Comprende code switching? young Mexican-Americans' responses to language alternation in print advertising. Journal of Advertising Research, 51(4), 648.

Berg, B.L. (2001). Qualitative research methods for the social sciences. Boston, MA: Allyn and Bacon.

Blair, J. (2004). The rhetoric of visual arguments. In C.A. Hill \& M. Helmers (Eds.), Defining visual rhethorics (pp. 41-91). Mahwha, NJ: Erlbaum.

Blejer, M. Levy-Yeyati, E. (2010, July 21). Leaving the Euro: What's in the box?. Retrieved from http://www.voxeu.org/article/leaving-euro-lessons-argentina

Bryman, A. (2008). Social research methods. New York, NY: Oxford University Press.

Castano, I (2011). Latin America's Luxury Market Seen Booming. WWD: Women's Wear Daily, 202(131), 11-1. Retrieved from Textile Technology Complete. 
Castano Freeman, I. (2012). just-style management briefing: Latin America luxury market could overtake China. Retrieved from http://www.just-style.com/management-briefing/latinamerica-luxury-market-could-overtake-china_id115104.aspx

Chevalier, M., \& Lu, P. X. (2010). Luxury china: Market opportunities and potential. Hoboken, N.J: John Wiley \& Sons (Asia). Print.

Chevalier, M., \& Mazzalovo, G. (2008). Luxury brand management: A world of privilege. Singapore: John Wiley \& Sons (Asia). Print.

Comerial La Nación (2010, September 10). Brando. Retrieved from http://www.comerciallanacion.com.ar/pages/productocomercial.aspx?cat=revista

Condé Nast. (N. D.). Nuestros Títulos / Vogue Latinoamérica. Retrieved from http://condenast.com.mx/vo_demograficos_lat.php

Conspicuous Consumption. (2008). In Encyclopedia of Social Problems online. Retrieved from http://www.credoreference.com.www.libproxy.wvu.edu/entry/sagesocprob/conspicuous consumption

Davis, C.H. \& R. Khare (2002). Segmenting the Tourism Destination Product: a Q Method Study of Bay of Fundy Summer Visitor Travel Experience Preferences. Proceedings of the 2002 Atlantic Schools of Business Conference, Antigonish.

Dewar, K., Davis, C. (2005). Photographic images, culture, and perception in tourism advertising: a study of Canadian and Chinese university students using Q-methodology. Journal of Travel and Tourism Marketing, 22(2), 35-44.

Dilley, R. S. (1986) Tourist Brochures and Tourist Images. Canadian Geographer, 30(1), 59-65.

Doran, S. (2012, Aug 14). Prosperous Times for Luxury Print Media, Or Are They?. Retrieved from http://luxurysociety.com/articles/2012/08/prosperous-times-for-luxury-print-mediaor-are-they

Dubois, B, \& Duquesne, P. (1993). The market for luxury goods: Income versus culture. European Journal of Marketing, 27(1), 35-44.

Dutta-Bergman, M. J., \& Wells, W. D. (2002). The values and lifestyles of idiocentrics and allocentrics in an individualist culture: A descriptive approach. Journal of Consumer Psychology, 12(3), 231-242.

Edwards, H., Day, D. (2005). Creating passion brands: Getting to the heart of branding. Sterling, VA: Kogan Page. Print.

Elo, S., \& Kyngäs, H. (2008). The qualitative content analysis process. Journal of Advanced Nursing, 62(1), 107-115.

Fitzgerald, T. (2011, January 11). Among magazines, haves are doing well. Luxury advertising is up, as are ad pages of luxury titles. Retrieved from http://www.medialifemagazine.com/among-magazines-haves-are-doing-well/

Fionda, A.M., Moore, C. (2009). The anatomy of the luxury fashion brand. Journal of Brand 
Management, 16(5-6), 347-363.

Frazer, C. F., Sheehan, K., \& Patti, C. H. (2002). Advertising strategy and effective advertising: comparing the USA and Australia. Journal Of Marketing Communications, 8(3), 149164.

Gomelsky, V. (2004). To understand the concept of luxury, forget the price. National Jeweler, 98(11), 12.

Graber, D. (1996). Say it with pictures. The Annals of the American Academy, 546, 85-96.

Haig, M., \& Books, I. (2004). Brand royalty: How the world's top 100 brands thrive and survive. Sterling, Va: Kogan Page. Print.

Hansen, A., Cothe, R., Negrine, R., Newbold, C. (1998). Mass communication research methods. New York, NY: NYU Press.

Hanson, P. (1974) Advertising and Socialism: The Nature and Extent of Consumer Advertising in the Soviet Union, Poland, Hungary and Yugoslavia. London: Macmillan Press.

Helft, D. (2012), Luxury Brands Leave Argentina in Droves. Fortune, CNN Money. Retrieved from http://finance.fortune.cnn.com/2012/09/19/luxury-brands-leave-argentina/

Hirschman, E. C., \& Holbrook, M. B. (1982). Hedonic consumption: Emerging concepts, methods and propositions. The Journal of Marketing, 46(3), 92-101.

Hornikx, J., Van Meurs, F \& de Boer, A. (2010). English or a local language in advertising?: The appreciation of easy and difficult English slogans in the Netherlands. Journal of Business Communication, 47(2), 169-188.

Johnston, D. C. \& Tieh, P. (1983). Projected and perceived images of tourist destinations in Asia and the Pacific In: Issues in tourism research in the South Pacific. Cahiers du Tourisme, $B(44), 11-14$.

Kapferer, J., \& Bastien, V. (2009). The specificity of luxury management: Turning marketing upside down. Journal of Brand Management, 16(5-6), 311-322. doi: 10.1057/bm.2008.51

Keller, K. L. (2009). Managing the growth tradeoff: Challenges and opportunities in luxury branding. Journal of Brand Management, 16(5-6), 290-301.

Knobloch-Westerwick, S. \& Coates, B. (2006). Minority models in advertisements in magazines popular with minorities. Journalism and Mass Communication Quarterly, 83(3), 596614.

Krippendorf, K. (2004). Content analysis: An introduction to its methodology. Thousand Oaks, CA: Sage.

Kritski, E. (2012, February 13). Media content analysis and social media research. Retrieved from http://gwstage.embanet.com/mod/book/view.php?id=1289

Kroll, C. (2009). P\&G introduces line with "tango passion": Both mass and luxury products find 
success in latin america. Global Cosmetic Industry, 177(1), 25.

Kotler, P., \& Armstrong, G. (2008). Principles of marketing (12th ed.). Upper Saddle River, NJ: Prentice Hall.

Krugman, D., King, K. (2000). Teenage exposure to cigarette advertising in popular consumer magazines. Journal of Public Policy \& Marketing, 19, 183-188.

Krugman, D., Morrison, M., Sung, Y. (2006). Cigarette Advertising in Popular Youth and Adult Magazines: A Ten-Year Perspective. Journal of Public Policy \& Marketing, 25(2), $197-$ 211

Lancaster, A., Lancaster, K. (2003). Teenage exposure to cigarette advertising in popular consumer magazine: vehicle versus frequency. Journal of advertising, 32(3), 69-76.

Luna, D., \& Peracchio, L. (2005). Advertising to bilingual consumers: The impact of CodeSwitching on persuasion. The Journal of Consumer Research, 31(4), 760-765.

Lee, T., Chung, W., \& Paik, C. (2011). Understanding your retirement savings: How the recent economic recession changed advertising in retirement financial services.(original aricle). Journal of Financial Services Marketing, 16(3-4), 244.

Mayring, P. (2000). Qualitative content analysis. Forum: Qualitative social research, 1(2), 120130. Retrieved from http://www.qualitativeresearch.net/index.php/fqs/article/view/1089/2386

Matthiesen, I., \& Phau, I. (2005). The 'HUGO BOSS' connection: Achieving global brand consistency across countries. Journal of Brand Management, 12(5), 325-338.

McCracken, G. (1986). Culture and consumption: A theoretical account of the structure and movement of the cultural meaning of consumer goods. The Journal of Consumer Research, 13(1), 71-84.

Messaris, P. (1997). Visual persuasion: the role of images in advertising. Thousand Oaks, CA: Sage.

Michigan State University. (N.D.). Argentina: Economy. Retrieved from https://globaledge.msu.edu/Countries/Argentina/economy

Nath, S. (2011). A public relations approach to exploring consumer behavior behind luxury purchases. University of Southern California. Print.

Neuendorf, K. A. (2002). The content analysis guidebook. Thousand Oaks, CA: Sage

Neuendorf, K. A., Skalski, P.D. (2010, May 23). Extending the Utility of Content Analysis via the Scientific Method. Retrieved from http://manoa.hawaii.edu/ccpv/workshops/NeuendorfSkalskiHawaii070810.pdf

Nguyen, A, Heeler, R M., \& Taran, Z. (2007). High-low context cultures and price-ending practices. Journal of Product \& Brand Management, 16(3), 206-214.

Noriega, J. \& Blair, E. (2008). Advertising to bilinguals: Does the language of advertising 
influence the nature of thoughts? Journal of Marketing, 72(5), 69-83.

Paivio, A. (1979). Imagery and verbal processes. Hillsdale, NK: Erlbaum.

Pisani, S. Condena del gobierno de EE.UU. al cepo publicitario. (2013, March 12). La Nación. Retrived from www.lanacion.com

Pollay, R.W. (1985) The subsiding sizzle: A descriptive history of print history, 1900-1980. Journal of Marketing 49(Summer): 24-37.

Por los recargos en tarjetas, el gasto de los argentinos en el exterior cayó 13,9\% (2012, November 6). La Nación. Retrived from www.lanacion.com

Potter, D.M. (1954) People of Plenty: Economic Abundance and the American Character. Chicago, IL: University of Chicago Press.

Pou, P. (2000). Argentina's Structural Reforms of the 1990s. Finance \& Development, 37(1).

Riffe, D., Lacy, S., Fico, F. (1998). Analyzing messages using quantitative content analysis in research. London, UK: Lawrence Erlbaum Associates.

Rodrik, D. (2003). Argentina: A Case of Globalisation Gone Too Far or Not Far Enough?. The New Republic. Retrieved from http://80-69-87192.colo.transip.net/uploaded/Argentina/Fondad-Argentina-Chapter2.pdf

Ryu, G., Park, J., \& Feick, L. (2006). The role of product type and country-of-origin in decisions about choice of endorser ethnicity in advertising. Psychology and Marketing, 23(6), 487513.

Schill, D. (2012). The visual image and the political image: A review of visual communication research in the field of political communication. Review of Communication, 12:2, 118142.

Seldon, J.J. (1963). Advertising in the Twentieth: The Golden Fleece Selling the Good Life to Americans. New York, N.Y.: McMillan.

Snyder, M., DeBono, K. (1985). Appeals to image and claims about quality: Understanding the psychology of advertising. Journal of Personality and Social Psychology, 49(3), 586-597.

Shankar, S. (2012). Creating model consumers: Producing ethnicity, race, and class in Asian American advertising. American Ethnologist, 39(3), 578-591.

Skorek, M., \& Dunham, Y. (2012). Self-enhancement following exposure to idealized body portrayals in ethnically diverse men: A fantasy effect of advertising. Sex Roles, 66(9), 655-667.

Sung, Y., \& Hennink-Kaminski, H. J. (2008). The master settlement agreement and visual imagery of cigarette advertising in two popular youth magazines. Journalism \& Mass Communication Quarterly, 85(2), 331-352

Total Medios. (N. D.). Para Tí. Retrieved from http://www.totalmedios.com/medio/371/para-ti 
Tung, R. L., \& Verbeke, A. (2010). Beyond hofstede and GLOBE: Improving the quality of cross-cultural research. Journal of International Business Studies, 41(8), 1259-1274.

Okonkwo, U. (2007). Luxury fashion branding: Trends, tactics, techniques. Basingstoke, [UK]: Palgrave Macmillan.

van Rompay, T., de Vries, P. W., Bontekoe, F., \& Dijkstra, K. (2012). Embodied product perception: Effects of verticality cues in advertising and packaging design on consumer impressions and price expectations. Psychology \& Marketing, 29(12), 919-928.

Viteri, A. (N.D.). Why RightSource to South America?. Retrieved from http://www.neubloc.com/news.asp?nid=9

Weber, R. (1990). Basic content analysis. Thousand Oaks, CA: Sage.

Webber, J. (2011). Argentina adds import restrictions to 200 goods. FT.Com

Wilcox, K., Kim, H. M., \& Sen, S. (2009). Why do consumers buy counterfeit luxury brands? Journal of Marketing Research,46(2), 247-259.

Würtz, E. (2005). A cross-cultural analysis of websites from high-context cultures and lowcontext cultures. Journal of Computer-Mediated Communication, 11(1), 0-0.

Zurawicki, L., \& Braidot, N. (2005). Consumers during crisis: Responses from the middle class in argentina. Journal of Business Research, 58(8), 1100-1109. 


\section{APPENDIX I. CODING SCHEME}

Global and Domestic Luxury advertising - Content analysis coding scheme

1. Ad ID:

2. Coder: 1)

2)

\section{A. Ad Types}

3. Magazine:

(1) PTC

(2) Vogue

(3) Brando

4. Magazine issue Year:

5. Month:

6. Advertised Luxury Brand Name:
A. International Luxury Brands
(1) Anna Sui
(2) Audi
(3) Balenciaga
(4) Bally
(5) Bang and Olufsen
(6) BMW
(7) Bulgari
(8) Burberry
(9) Cadillac
(10) Calvin Klein
(11) Cartier
(12) Celine
(13) Chanel
(14) Chaumet
(15) Chloe
(16) Christian Dior
(17) DAKS
(19) Donna Karan
(20) Elizabeth Aden
(18) Dolce \& Gabbanna
(22) Escada
(23) Estee Lauder
(21) Ermenegildo Zegna
(25) Fendi
(28) Givenchy
(26) Ferragamo
(24) Etro
(29) Gucci
(27) Giorgio Armani
(31) Hermes
(32) Hugo Boss
(30) Guerlain
(34) Jaguar
(35) Jimmy Choo
(33) Infinniti
(37) La Praire
(38) Lancome
(36) La Mer
(40) Lexus
(41) Lincoln
(39) Lanvin
(43) Mercedes Benz
(44) Michael Kors
(46) Miu Miu
(47) Omega
(42) Louis Vitton
(49) Ralph Lauren
(50) Rolex
(45) Missoni
(48) Prada
(52) Sisley
(53) Swarovski
(55) Tiffany \&Co.
(56) Tissot
(51) Shiseido
(58) Versace
(59) Volvo
(54) TAU Heuer
(57) Valentino
(60) Yves Saint Laurent

(61) Others

B. Argentine Luxury Brands
(1) Aló Martínez
(2) Akiabara
(4) Ayres
(5) Benito Fernández
(7) Bensimon
(8) Bowen
(10) Caro Cuore
(11) Class Life

(3) Ay Not Dead Martínez

(6) Blaqué

(9) Cardón

(12) Como quieres que te quiera 
(13) Complot

(16) Etiqueta Negra

(19) Jazmin Chebar

(22) Little Akiabara

(25) MAB

(28) Mimo \& Co.

(31) Ona Saez

(34) Paruolo

(36) Portsaid

(39) Ricky Sarkany

(42) VER

(45) XL
(14) Cook

(17) India Style

(20) La Cofradía

(23) Las Pepas

(26) María Vazquez

(29) Muaa

(32) Orgullosa María

(34) Paula Cahen D'Anvers

(37) Prune

(40) Tucci

(43) Vitamina

(46) Yagmour
(15) Desiderata

(18) Giesso

(21) La Martina

(24) Las Oreiro

(27) Macowens

(30) Old Bridge

(33) Ossira

(35) Peuque

(38) Rapsodia

(41) Uma

(44) Wanama

(47) Others

7. Advertised Luxury Brand Category (check only one major product category) (Fionda and Moore 2009; Henderson \& Baldasty 2003)

\begin{tabular}{|l|l|l|}
\hline (1) Fashion(clothing/shoes/bags) & (2) Perfumes and cosmetics & (3) Watches \\
\hline (4) Jewelry and accessories & (5) Automobiles & (6) Wines and spirits \\
\hline (7) Others: Specify & & \\
\hline
\end{tabular}

\section{B. Appeals}

Function and Image appeals (Wilcox, Kim \& Sen, 2009)

(Check all that apply: Check "1" when the following appeal is used; Cheek "0 when is NOT)

\begin{tabular}{|c|c|c|c|}
\hline & & $\begin{array}{l}(0) \\
\text { No }\end{array}$ & $\begin{array}{l}(1) \\
\text { Yes }\end{array}$ \\
\hline 8 & $\begin{array}{l}\text { Function-oriented appeal (It emphasizes the consumer's practical, functional, and } \\
\text { utilitarian need, such as quality and reliability of products) }\end{array}$ & 0 & 1 \\
\hline 9 & $\begin{array}{l}\text { Image-oriented appeal (It emphasizes image-related aspects of products such as a } \\
\text { particular image of a brand in a society or a symbol of a society) }\end{array}$ & 0 & 1 \\
\hline
\end{tabular}

10. Does the ad use emotions as the basis of messages such as fear, happiness, joy, etc? (Frazer, Sheehan, \& Patti, 2002)

(0) No (1) Yes

If the ad uses emotions, to what type of emotions described below are depicted?

\begin{tabular}{|c|c|c|c|}
\hline & Types of emotions & $(0)$ & $(1)$ \\
& & No & Yes \\
\hline
\end{tabular}




\begin{tabular}{|l|l|l|l|}
\hline 11 & Cheerful emotions: happiness, elation, joy, excitement, delight, gladness & 0 & 1 \\
\hline 12 & Quiescent emotions: calmness, placidness, restfulness, peacefulness, relief & 0 & 1 \\
\hline 13 & Dejection: sadness, regret, disappointment, depression, shame, blame, worthless & 0 & 1 \\
\hline 14 & Agitation: stress, tension, anxiety & 0 & 1 \\
\hline
\end{tabular}

\section{Strategies and messages of ad}

(Check all that apply: Check "1" when the following messages are emphasized in the ad; Cheek "0 when is NOT)

\begin{tabular}{|c|c|c|c|}
\hline & & $\begin{array}{l}\text { (0) } \\
\text { No }\end{array}$ & $\begin{array}{l}\text { (1) } \\
\text { Yes }\end{array}$ \\
\hline 15 & $\begin{array}{l}\text { Product performance: Directly address the product performance (show or } \\
\text { explain how the product functions) }\end{array}$ & 0 & 1 \\
\hline 16 & $\begin{array}{l}\text { Utilitarian Need: Address the consumer's practical and utilitarian needs/ } \\
\text { effectiveness of products }\end{array}$ & 0 & 1 \\
\hline 17 & Ingredient of products: Explicit mention of product ingredient & 0 & 1 \\
\hline 18 & Economical Value: Address the consumer's economic benefits & 0 & 1 \\
\hline 19 & $\begin{array}{l}\text { Self-esteem/ self-images of products usage: Being different from others or } \\
\text { standing out/ emphasis on the unique personality, originality }\end{array}$ & 0 & 1 \\
\hline 20 & $\begin{array}{l}\text { Accomplishment and achievement: Reflection of self fulfillment, self } \\
\text { development, personal success or personal goal achievement }\end{array}$ & 0 & 1 \\
\hline 21 & Sexual images of products & 0 & 1 \\
\hline 22 & $\begin{array}{l}\text { Modern/contemporary looks of products: New, modern, innovative, improved, } \\
\text { progressive products }\end{array}$ & 0 & 1 \\
\hline 23 & $\begin{array}{l}\text { Technological aspects of products: Technological, engineered, and resulting } \\
\text { from science, invention, discovery, or research }\end{array}$ & 0 & 1 \\
\hline 24 & Safety, secured image of products: Address safety and stability of products & 0 & 1 \\
\hline 25 & $\begin{array}{l}\text { Trendy: There is a slight sense of chaos to this type. The model has an "I-don't- } \\
\text { give-a-darn attitude" }\end{array}$ & & \\
\hline 26 & Relaxed/comfortable: Relaxed and restful, being laid back images of products & 0 & 1 \\
\hline 27 & $\begin{array}{l}\text { Social Approval: Associated a product usage with a particular situation, type of } \\
\text { person, or lifestyle }\end{array}$ & 0 & 1 \\
\hline 28 & $\begin{array}{l}\text { Symbolic meaning: Address symbolic meaning/ impressions of the product in a } \\
\text { society. }\end{array}$ & 0 & 1 \\
\hline
\end{tabular}

\section{Language}

29. Does the ad use more than one language? (0) No

(1) Yes 
30. Indicate all languages used: (All that apply)

a. (1) Spanish (2) Italian (3) French (4) English (5) Other (6) Not sure

b. (7) No written language used other than brand logos and symbols (visuals only)

E. Characteristics of Human Models in the ad (Sung and Hennink-Kaminski, 2008)

31. Human models in the ad?

(0) Not present

(1) Present (If "Not", skip this section.)

32. How many male human models in the ad? ( )

33. How many female human models in the ad? ( )

\section{For Race and Characteristics}

Code through subjective determinations based on visual cues (skin color and facial features). When two or more models appear in an advertisement, code the one who is perceived to be the central character. If no obvious central character is in existence, the analyst assigns a number to each model (e.g. one to four) and selects one of these randomly using the generator available at www.randomnumbergenerator.com, for inclusion in the sample. Thus, only the number thrown by the website should be analyzed. In short, the unit of analysis is the central character in a full-page advertisement.

34. Race of human models Race: (CIA Factbook, 2008) - See pictures below for further reference

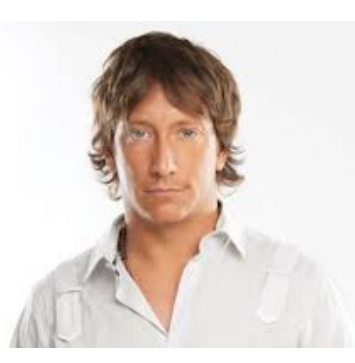

-White-
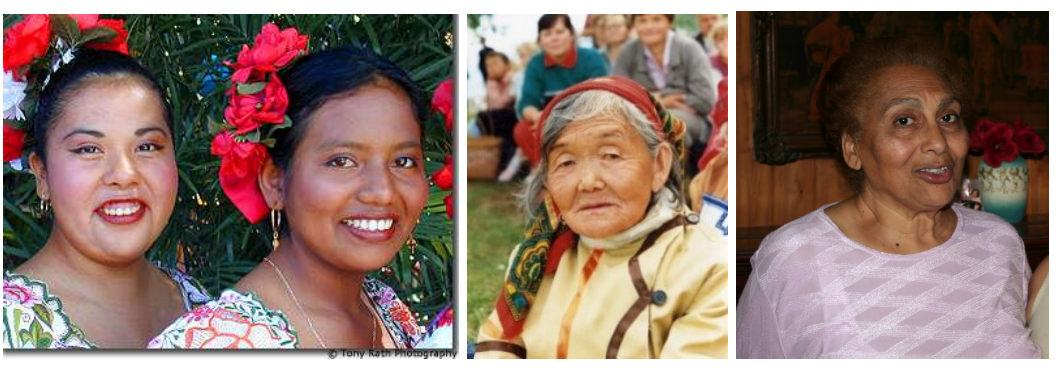

-Mestizo-

-Amerindian- -Other non-white-

1) White - a person of European descendent

2) Mestizo - a person of mixed raced

3) Amerindian - any member of the peoples living in North or South America before the Europeans arrived

4) Other: Specify 
F. Visual cues (Sung \& Hennink-Kaminski, 2008)

35. Ad Sizes: (1) Less than $1 / 2$ page

(4) more than 1 page less than 2

(2) less than 1 page

(3) 1 page

(6) more than 2 pages pages)

36. Ad Illustration: (1) Artwork

(2) Photos

(3) Combination artwork / photos

(4) No visuals/all copy

37. Visual/Verbal Balance (choose closest one):

(1) No Words

(3) $1 / 4$ words and $3 / 4$ pictures

(2) Some words but less than $1 / 4$ words

(5) $3 / 4$ words and $1 / 4$ pictures

(7) No pictures

(4) $1 / 2$ words and $1 / 2$ pictures

(6) Less than $1 / 4$ pictures

38. Settings in human model(s) depicted. (van Rompay, de Vries, Bontekoe, \& Dijkstra; 2012)

1) Business/sales (retail settings in which consumers are depicted inside bank/financial institutions)

2) Home/indoor (recognizable as a residence, room at home, garage, yard, or parking space)

3) Outdoor/natural scenery (includes forests, rivers, ocean, fields, or sky as well as streets, public roads, sidewalks, or pathways, Does not include outdoor settings at individual's home)

4) Social setting outside home (includes public places such as auditoriums, churches, classrooms, stadiums, libraries, restaurant, or move theaters. Where people meet for social purposes.)

5) Others: Specify

39. What is the setting/location of the advertisement?

1) Local theme - the background depicted recreates the Argentine culture, landscape or architecture. E.g., Iguazu Falls, Obelisco in Buenos Aires, Quebrada de Humahuaca.

2) International theme - the background depicted clearly denotes an international setting. E.g.: Eiffel Tower, the Central Park, Caribbean Beach, etc.

3) Studio setting - the subjects pose in front of an artificial background, such as cloths or are superposed on a background impossible to capture through a real-life photography session, such as the space.

4) Illustrated background - the background is the result of graphic design

5) No background - e.g. the models are superposed over a solid background such as all white.

6) Other: 
40. How is the camera angle of the background in the ad?

1) Horizontal

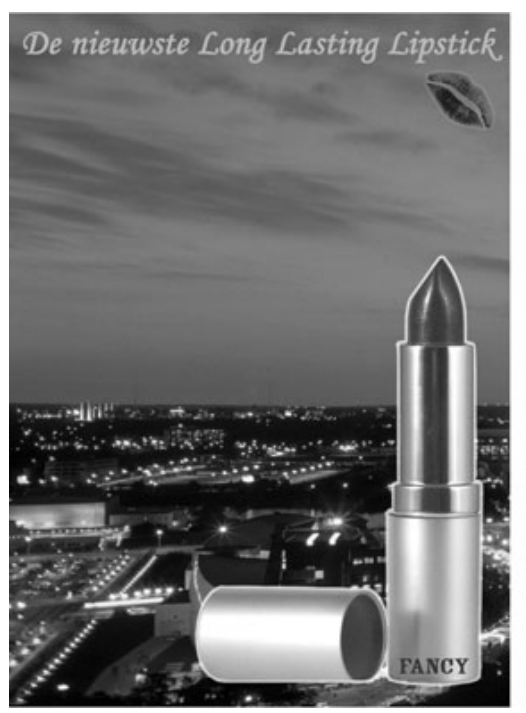

2) Vertical

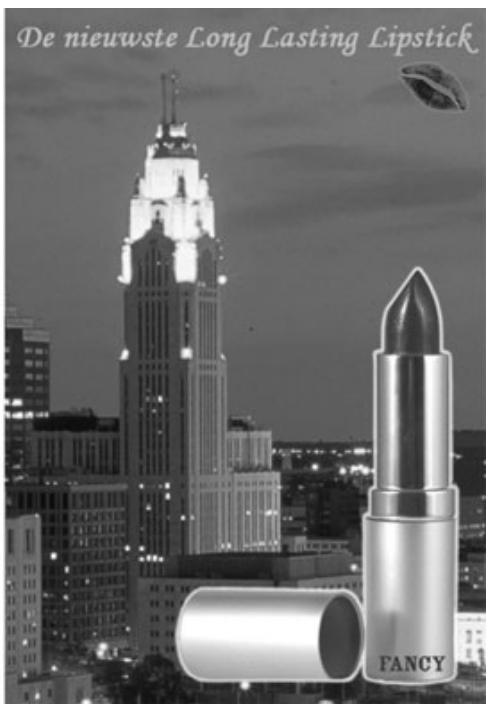

41. How is the camera angle of the product in the ad?

1) Horizontal

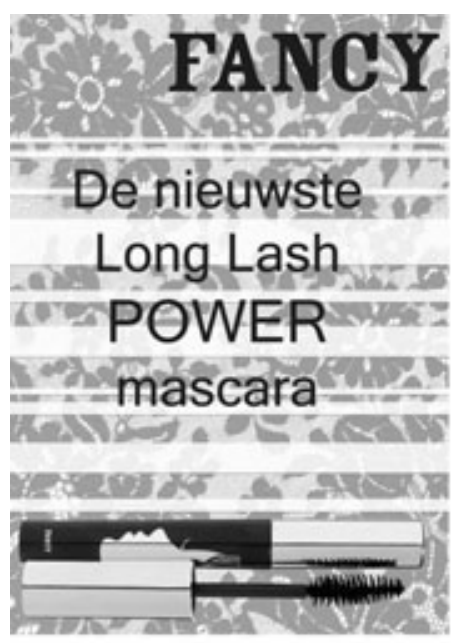

2) Vertical

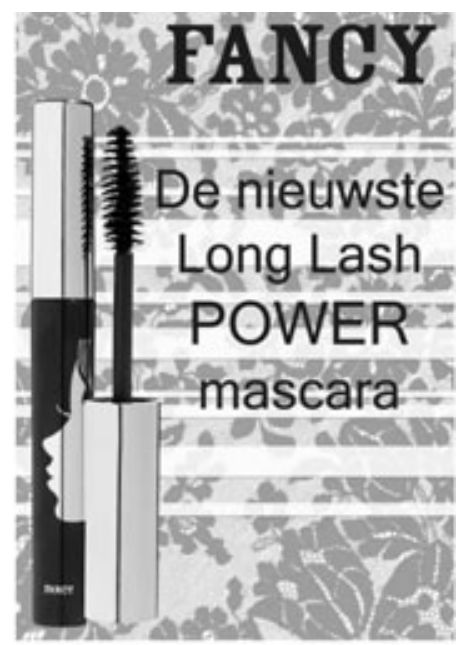

